Gut, 1974, 15, 1-8

\title{
Amino acid and peptide absorption in patients with coeliac disease and dermatitis herpetiformis
}

\author{
D. B. A. SILK, PARVEEN J. KUMAR, D. PERRETT, M. L. CLARK, AND \\ A. M. DAWSON \\ From the Departments of Medicine and Gastroenterology, St Bartholomew's Hospital, London, \\ and St Leonard's Hospital, London
}

SUMmaRY A double-lumen perfusion technique has been used to study amino acid and peptide absorption in eight normal control subjects, 13 patients with untreated adult coeliac disease, and 16 patients with dermatitis herpetiformis who had varying morphological abnormalities of the small bowel. All subjects were perfused with isotonic solutions containing $10 \mathrm{mM}$ glycyl-L-alanine and $10 \mathrm{mM}$ glycine $+10 \mathrm{mM}$ L-alanine.

Patients with adult coeliac disease had impaired absorption of glycine $(\mathrm{P}<0.01)$ and L-alanine $(P<0.05)$ from the amino acid solution compared with the control subjects. Amino acid uptake from the dipeptide solution was not significantly impaired, although four individual patients had impaired uptake of both amino acids. In contrast to these findings, very few patients with dermatitis herpetiformis had impaired amino acid absorption from either solution.

Sodium absorption was impaired from both solutions when the groups of patients with adult coeliac disease and dermatitis herpetiformis with subtotal villous atrophy and partial villous atrophy were studied, and there were patients in each group who secreted sodium and water.

The results suggest that malabsorption of dietary protein is unlikely to occur in dermatitis herpetiformis but may occur and contribute to protein deficiency seen in some severe cases of adult coeliac disease. The impairment of sodium and water absorption provides evidence that there may be functional impairment of the jejunal mucosa in dermatitis herpetiformis as well as in adult coeliac disease.

Protein deficiency which can be severe may be seen in some patients with untreated adult coeliac disease. Protein deficiency is usually attributed to a combination of anorexia, malabsorption of protein, and excessive loss of endogenous protein into the alimentary tract. The extent to which malabsorption of protein contributes to protein deficiency is not clear. Oral load techniques have indicated that there may be a delay in absorption of amino acids and small peptides (Craft, Geddes, Hyde, Wise, and Matthews, 1968), and the products of intraluminal digestion of yeast protein and a yeast protein hydrolysate (Crane and Neuberger, 1960a and b). Impaired amino acid absorption from the proximal small intestine has also been shown using a perfusion technique (Schedl, Pierce, Rider, and Clifton, 1968). In contrast, normal plasma amino acids levels were found when patients with adult coeliac disease were

Received for publication 25 September 1973. fed casein (Richmond and Girdwood, 1962), and elevated plasma amino acid levels were seen when such patients were fed gluten and albumen (Douglas and Booth, 1969).

It has been shown in animals (Matthews, Craft, Geddes, Wise, and Hyde, 1968; Rubino, Field, and Shwachman, 1971; Matthews, 1971) and confirmed in man (Asatoor, Cheng, Edwards, Lant, Matthews, Milne, Navab, and Richards, 1970; Adibi, 1971; Hellier, Holdsworth, McColl, and Perrett, 1972; Silk, Perrett, and Clark, 1973) that the products of intraluminal protein digestion, free amino acids and small peptides, may be absorbed by two separate transport systems. It is likely that most peptides are hydrolysed to free amino acids by mucosal cell peptide hydrolase enzymes, as to date only low concentrations of one peptide, glycylglycine, have been detected in human peripheral plasma (Adibi, 1971). Patients with adult coeliac disease have reduced jejunal mucosal peptide hydrolase activity per unit 
area (Lindberg, Nordén, and Josefsson, 1968; Berg, Dahlqvist, Lindberg, and Nordén, 1970; Douglas and Peters, 1970), which might influence absorption of dietary protein. In view of these observations, amino acid and dipeptide absorption has been studied in patients with adult coeliac disease. A steady state jejunal perfusion technique has been used, and glycine and L-alanine absorption from the dipeptide glycyl-L-alanine and equivalent equimolar amino acid mixture compared. In order to study the effect of the amino acids and the dipeptide on sodium and water absorption, the perfusion solutions were rendered iso-osmotic by adding sodium chloride.

Patients with dermatitis herpetiformis have a similar although less severe and more variable mucosal abnormality compared with that seen in adult coeliac disease (Brow, Parker, Weinstein, and Rubin, 1971). We have used the same technique to study amino acid and dipeptide transport with concomitant sodium and water movement in a group of these patients in order to compare them with normals and patients with adult coeliac disease.

\section{Materials and Methods}

\section{SUBJECTS}

Thirteen patients with untreated adult coeliac disease with a mean age of 41 years (range 19-68) and 16 patients with dermatitis herpetiformis with a mean age of 39 years (range 28-62) were studied. The diagnosis of coeliac disease was established by history, physical examination, the usual laboratory criteria of malabsorption, and the typical histological appearance of the jejunal biopsy. All these patients subsequently showed clinical and morphological improvement when gluten was withdrawn from the diet. The diagnosis of dermatitis herpetiformis was established by history, physical and histological examination of the skin eruption, and response of the skin lesion to oral therapy with dapsone. All patients were studied before withdrawing gluten from the diet and dapsone therapy was withdrawn from 15 of 16 patients with dermatitis herpetiformis 48 hours before the study.

Eight normal adult volunteers, without evidence of gastrointestinal disease with a mean age of $\mathbf{4 0}$ years (range 21-64 years), acted as controls. The full purpose and nature of the study was explained to all subjects and informed consent to the study was given in each case. The approval of the local Ethical Committee was obtained to carry out the study on patients.

BIOPSY TECHNIQUES

Intestinal mucosal biopsies were obtained from all patients with adult coeliac disease and dermatitis herpetiformis using the biopsy capsule of Crosby and Kugler (1957). The biopsies were taken under fluoroscopic control from a $10 \mathrm{~cm}$ segment of upper jejunum beyond the duodenal-jejunal flexure.

\section{MORPHOLOGICAL PROCEDURE}

Each biopsy was orientated on a ground glass slide and fixed in a $10 \%$ formaldehyde saline solution. They were then examined under a dissecting microscope and photographed. The histology was classified according to the criteria of Stewart, Pollock, Hoffbrand, Mollin, and Booth (1967), with particular reference to villous height, mucosal thickness, and epithelial surface cell height, and graded as normal, partial villous atrophy, or subtotal villous atrophy.

\section{EXPERIMENTAL TECHNIQUES}

The patients and four of the control subjects were intubated on the evening before the study with a double-lumen perfusion tube incorporating a proximal occlusive balloon (Sladen and Dawson, 1970). The remaining four control subjects were intubated on the morning of the study. The tube was allowed to pass until the infusion orifice was distal to the duodenal-jejunal flexure and the final position of the tube was checked fluoroscopically, so that the infusion orifice was situated in the $10-\mathrm{cm}$ segment of upper jejunum beyond the duodenal-jejunal flexure. A proximal occlusive balloon was incorporated in the perfusion tube in order to prevent both reflux of the infused solution out of the perfusion segment and to prevent contamination of the infused solutions within the perfused segment with proximal secretions, in particular pancreatic proteolytic enzymes. The efficiency of the occluding balloon was checked by injecting a $4 \mathrm{ml}$ bolus of phenol red every 30 minutes through an additional lumen opening immediately proximal to the balloon.

The perfusion solutions were pumped at $15 \mathrm{ml} / \mathrm{min}$ through the infusion orifice, using a peristaltic pump (H.R. flow inducer, Watson-Marlow Ltd, Marlow, Bucks) from bottles maintained at $37^{\circ} \mathrm{C}$ in a water bath. The first 30 minutes of each perfusion were allowed for the attainment of a steady state in absorptive rates, preliminary studies having indicated that this interval was sufficient for this purpose. Three 10-minute samples were collected from the distal collecting orifice by simple syphonage. The samples were collected into plastic bottles which were kept chilled in crushed ice and contained sufficient sulphosalicylic acid crystals to ensure a pH of approximately $2 \cdot 0$. Our own investigations have indicated that this procedure inactivates intraluminal peptide hydrolase activity. The aspirated samples were then filtered through Whatman no. 1 
filter paper and the filtrates stored at $-20^{\circ} \mathrm{C}$ until required for analysis.

The perfusion solutions contained either the dipeptide glycyl-L-alanine (Gly-Ala) at a concentration of $10 \mathrm{mM}$ or the equivalent $10 \mathrm{mM}$ equimolar mixture of the amino acids glycine (Gly) and Lalanine (Ala); the solutions were made iso-osmotic by adding sodium chloride, and contained the non-absorbable marker polyethylene glycol (PEG) at a concentration of $2.5 \mathrm{~g}$ per litre (Sched1, 1966). The $\mathrm{pH}$ of each solution was adjusted to 7 before perfusion by titrating with molar sodium hydroxide.

\section{LABORATORY MEASUREMENTS}

The amino acid and dipeptide content of the perfusion solutions and aspiration samples were quantitated using a Technicon NC-1 analyser and the buffer system of Purdie, Gravelle, and Hanafi (1968). The PEG content of the perfusion solutions and of the intestinal aspirates was measured by a turbidimetric method (Hydén, 1956). The sodium content of the perfusion solutions and of the intestinal aspirates was measured by using a flame photometer (EEL 227 flame photometer, Evans Electro Selenium Ltd, Halstead, Essex) and the osmolalities of the perfusion solutions were checked using an Advanced osmometer (Advanced Instruments Inc, Massachusetts, USA).

CALCULATIONS

The absorption rates of the amino acids from the amino acid solution, and the net amino acid absorption rates from the dipeptide solution were calculated from formulae previously described (Holdsworth and Dawson, 1964; Adibi, 1971).

\section{STATISTICS}

The statistical significance of the difference in absorption rates of the two amino acids from the amino acid solution and the dipeptide solution in the normal control subjects was evaluated by the paired $t$ test. The difference in absorption rates of the amino acids from the amino acid solution and dipeptide solution in the normal control subjects and the patients was evaluated by Wilcoxon's sum of ranks test and Wilcoxon's signed ranks test, where appropriate (Langley, 1968).

\section{Results}

\section{MORPHOLOGY}

All patients with untreated adult coeliac disease had subtotal villous atrophy (SVA) of the jejunal mucosa. Of the patients with dermatitis herpetiformis six had subtotal and nine had partial villous atrophy. One patient had normal jejunal morphology.

AMINO ACID ABSORPTION FROM THE AMINO ACID AND DIPEPTIDE SOLUTION

Normals

The rates of amino acid absorption from the dipep-

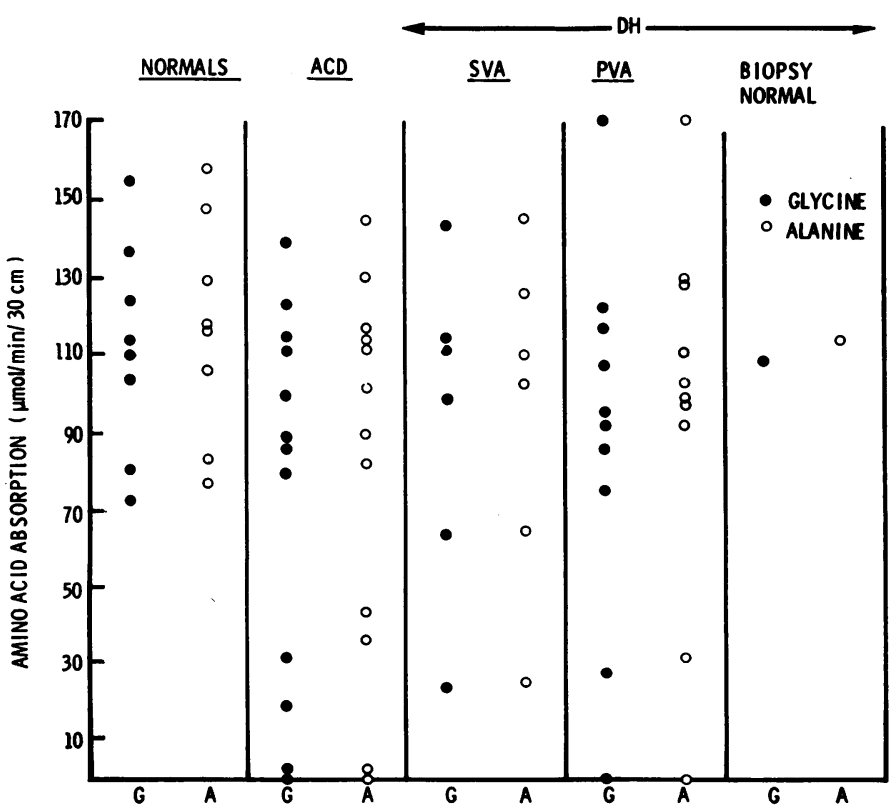

Fig 1 Absorption of glycine ( $G$, closed circles) and L-alanine ( $A$, open circles) from the upper jejunum observed when normal subjects and patients with untreated adult coeliac disease and dermatitis herpetiformis who had subtotal villous atrophy (SVA), partial villous atrophy $(P V A)$, and normal jejunal biopsies, were perfused with a solution containing $10 \mathrm{mM}$ glycyl-L-alanine. 


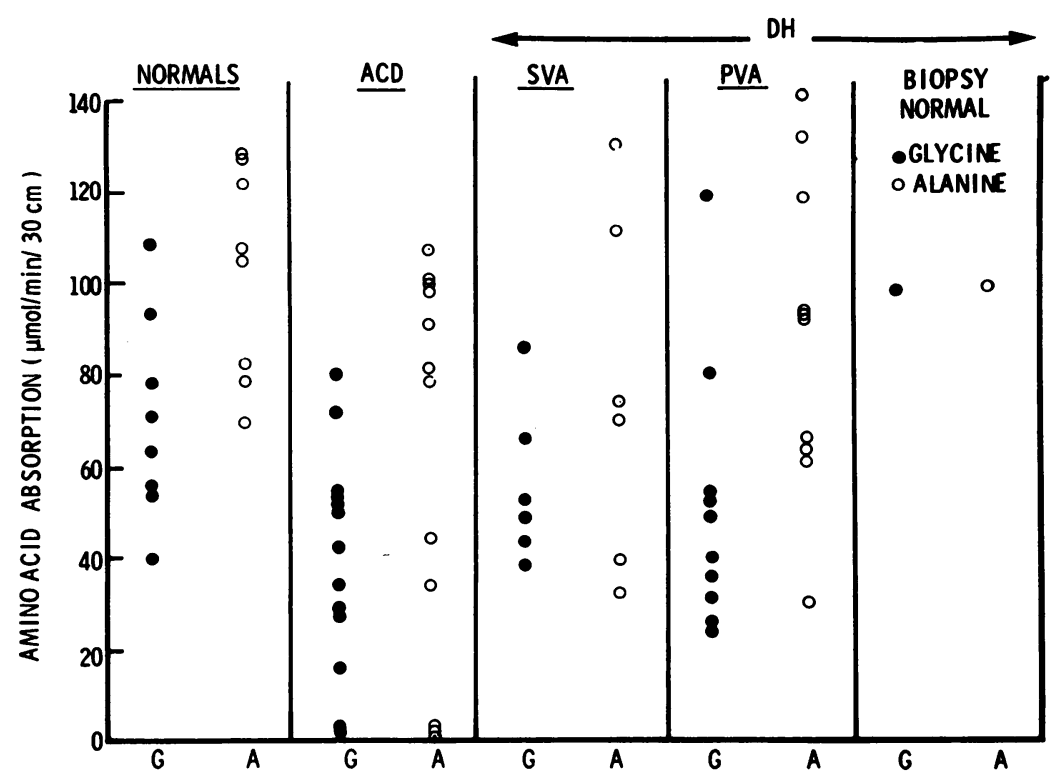

Fig 2 Absorption of glycine ( $G$, closed circles) and L-alanine ( $A$, open circles) from the upper jejunum observed when normal subjects and patients with untreated adult coeliac disease and dermatitis herpetiformis who had subtotal villous atrophy $(S V A)$, partial villous atrophy $(P V A)$, and normal jejunal biopsies were perfused with a solution containing $10 \mathrm{mM}$ glycine $+10 \mathrm{mM}$ L-alanine.

tide and equivalent amino acid solution are shown in figures 1 and 2 . Ala (103.2 \pm 44.6$)$ was absorbed faster than Gly $(70.7 \pm 43.9)$ when the amino acid mixture was perfused $(\mathrm{P}<0.001)$. Although Ala was absorbed at comparable rates from the dipeptide $(115 \cdot 8 \pm 56 \cdot 3)$ and amino acid solution (103.2 \pm 44.6) Gly was absorbed faster from the dipeptide solution (112.0 \pm 54.9) than from the amino acid solution $(\mathrm{P}<0.01$; values are the mean absorptive rates expressed as $\mu \mathrm{mol} \mathrm{min} \mathrm{m}^{-1} 30 \mathrm{~cm}^{-1} \pm 2 \mathrm{SD}$ ).

When the dipeptide solution was perfused, free amino acids were detected in addition to dipeptide in the aspirated luminal contents (fig 3). Higher concentrations of Gly $(0.42 \pm 0.28)$ were detected compared with Ala $(0 \cdot 16 \pm 0 \cdot 10, P<0.001$; values are the mean \pm 2 SD and are expressed as $\mathrm{mM}$ ).

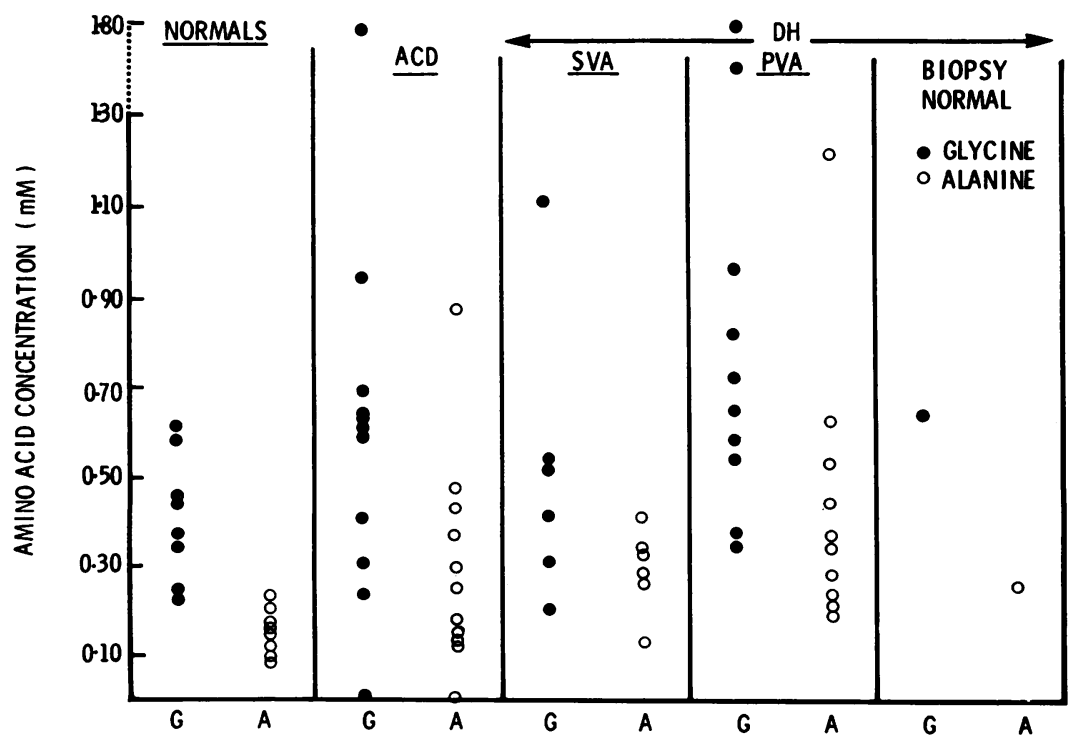

Fig 3 Concentrations of free glycine (closed circles) and Lalanine (open circles) detected in the luminal contents aspirated during perfusion of $10 \mathrm{mM}$ glycylL-alanine in normal subjects and patients with untreated adult coeliac disease and dermatitis herpetiformis who had subtotal villous atrophy (SVA), partial villous atrophy $(P V A)$, and normal jejunal biopsies. 
Adult coeliac disease

As a group Gly $(\mathrm{P}<0.01)$ and Ala $(\mathrm{P}<0.05)$ absorption from the amino acid solution was depressed compared with the control group. Three out of 13 patients had impaired uptake of both amino acids; one further patient had impaired Gly uptake, and two patients had impaired Ala uptake (values below 2 SD of the normal mean). Although as a group there was no consistent depression of Gly or Ala uptake from the dipeptide solution compared with the controls $(P>0.05)$, four out of 12 patients had impaired uptake of both amino acids from the dipeptide solution (values below 2 SD of the normal mean) and nine out of 12 values for Gly and Ala absorption were below the mean values observed when control subjects were perfused with the dipeptide solution. Of the four patients who had impaired uptake of both amino acids from the dipeptide solution, three had impaired absorption of both amino acids from the equivalent amino acid solution.

There was no significant difference in the concentration of free Gly and Ala detected in the luminal contents aspirated when the group of patients with adult coeliac disease was perfused compared with the controls, although two patients, who had impaired amino acid uptake from the amino acid mixture, had elevated levels of free Gly and Ala in the dipeptide aspirates (values greater than 2 SD of the normal mean). Neither Gly or Ala was detected in the aspirate of the dipeptide perfusate of the one patient who failed to absorb Gly or Ala from either solution.

\section{Dermatitis herpetiformis}

Compared with the normal control subjects there was no significant difference in the rates of Gly or Ala absorption when the groups of patients with subtotal and partial villous atrophy and normal jejunal morphology were perfused with the two solutions. One out of six patients with subtotal villous atrophy had impaired uptake of both amino acids from the dipeptide solution, and this patient also had impaired Ala uptake from the amino acid solution. In addition one further patient had impaired uptake of Ala from the amino acid solution. Two out of nine patients with partial villous atrophy had impaired uptake of both amino acids from the dipeptide solution; one of these patients also had impaired Ala absorption from the equivalent amino acid solution (values below $2 \mathrm{SD}$ of a normal mean).

Although there was no significant difference in the concentrations of free Gly detected in the dipeptide aspirates of the patients with subtotal villous atrophy compared with the controls, higher levels of free Ala were detected $(P<0.05)$. Higher concentrations of both Gly $(P<0.05)$ and Ala $(P<0.02)$ were detected in the dipeptide aspirates of the patients with partial villous atrophy. Of the six patients with subtotal villous atrophy, one had raised Gly concentration and five patients had elevated Ala

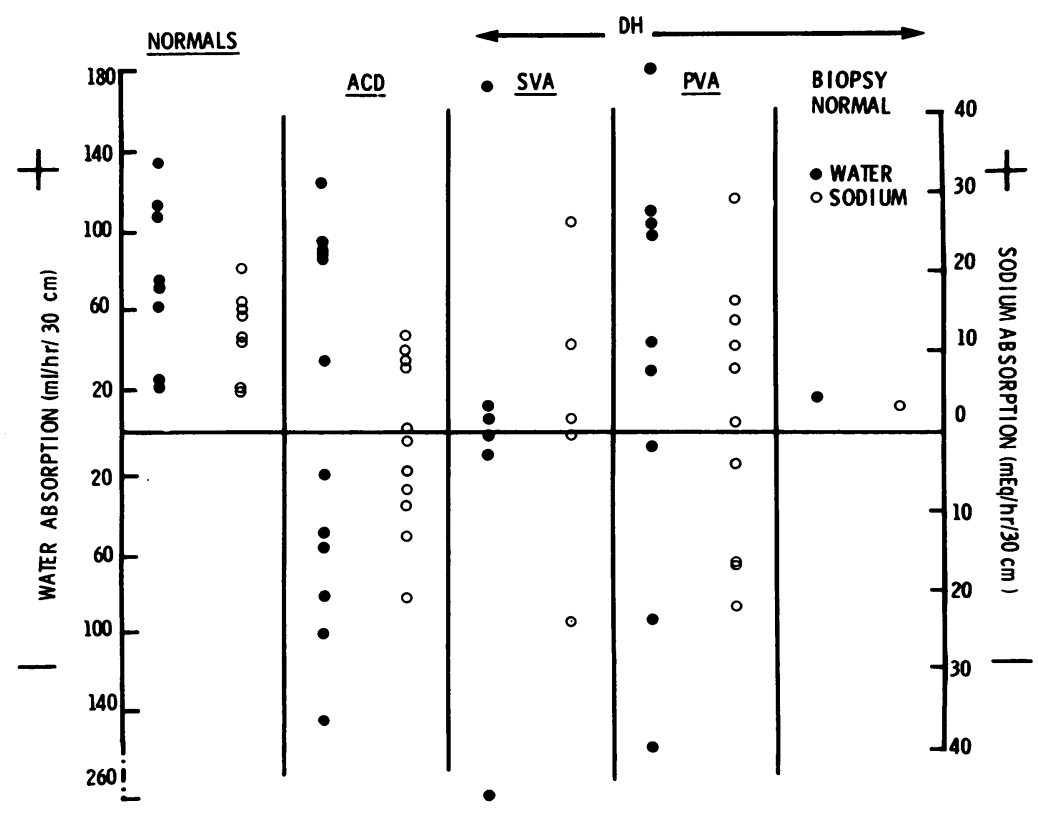

Fig 4 Sodium (open circles) and water (closed circles) absorption from the upper jejunum when normal subjects and patients with untreated adult coeliac disease and dermatitis herpetiformis who had subtotal villous atrophy $(S V A)$, partial villous atrophy $(P V A)$, and normal jejunal biopsies, were perfused with a solution containing 10 mM glycyl-L-alanine. + ve sign indicates net absorption and -ve sign indicates net secretion into the lumen of the small intestine. 


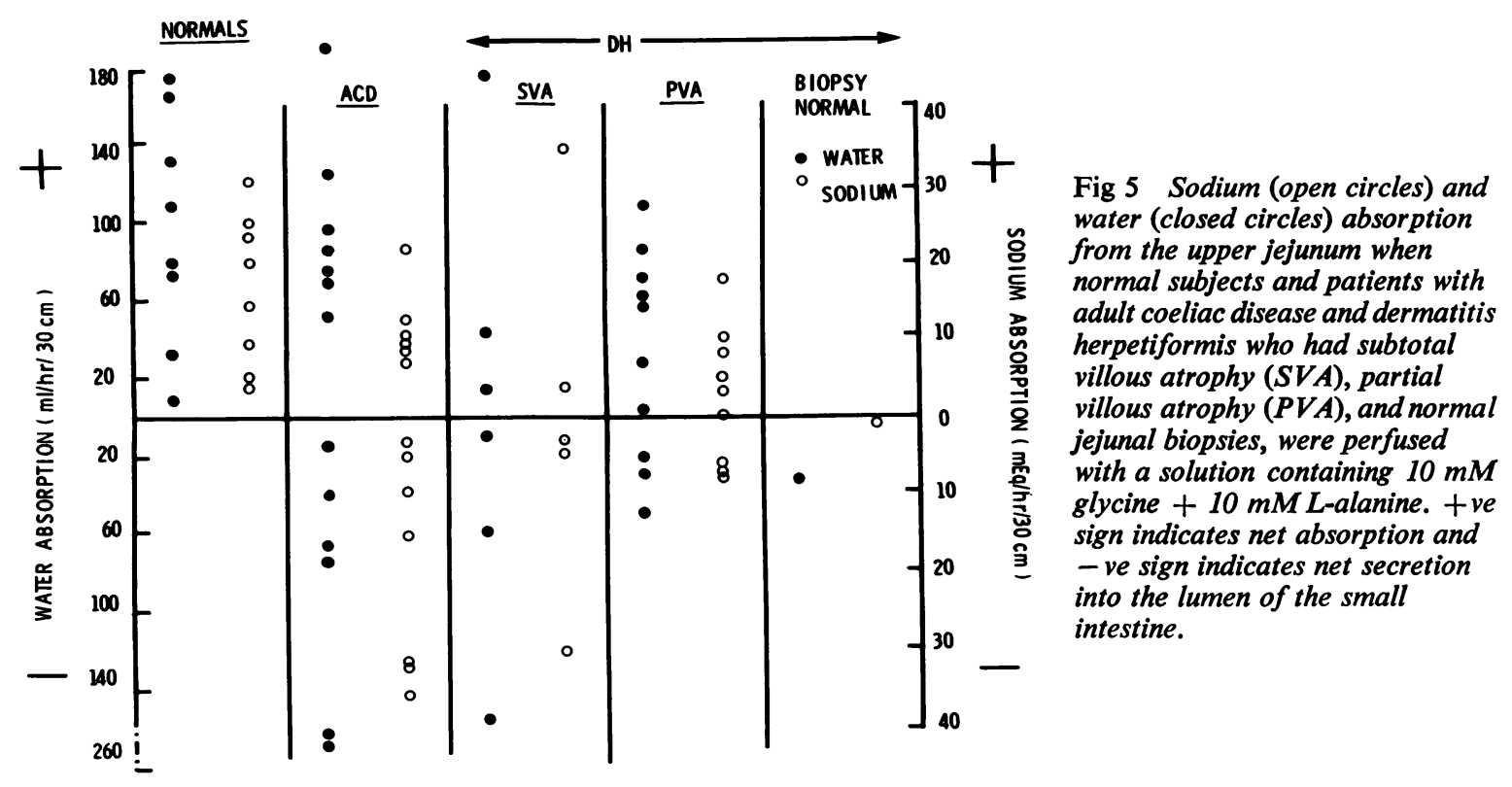

concentrations in the dipeptide aspirates. Of the nine patients with partial villous atrophy, four had elevated concentrations of Gly and Ala, and a further two had raised Ala levels (values above 2 SD of the normal mean).

\section{SODIUM AND WATER ABSORPTION}

\section{Normals}

The rates of sodium absorption from the dipeptide and amino acid solutions are shown in figures 4 and 5. There was no significant difference in sodium absorption from the amino acid solution (15.5 \pm 17.6) compared with that from the dipeptide solution $(12.9 \pm 11 \cdot 1)$. Values are the mean absorption rates expressed as m-equiv $\mathrm{hr}^{-1} 30 \mathrm{~cm}^{-1} \pm 2 \mathrm{SD}$. Similarly, there was no significant difference in water absorption from the amino acid solution (95.0 \pm 122.8$)$ compared with that from the dipeptide solution $(75.9 \pm 80.8$; values are the mean absorptive rates expressed as $\mathrm{ml} \mathrm{hr}^{-1} 30 \mathrm{~cm}^{-1} \pm 2 \mathrm{SD}$ ).

\section{Adult coeliac disease}

Sodium absorption was impaired from both the amino acid solution $(P<0.05)$ and the dipeptide solution $(P<0.01)$ (figs 4 and 5$)$. Four patients exhibited net secretion of sodium into the lumen of the small intestine during perfusion of both solutions. Two further patients exhibited net sodium secretion only during the amino acid perfusion, and two patients during the dipeptide perfusion (values below $2 \mathrm{SD}$ of the normal mean). There was no significant difference in water absorption from either solution compared with the control subjects, although the four patients who secreted sodium during perfusion of both solutions and the patients who secreted sodium during the perfusion of one of the two solutions also secreted water into the lumen of the small intestine.

With one exception, in every case where Gly and Ala uptake from the dipeptide or amino acid solution was impaired (values below 2 SD of the normal mean) sodium and water were secreted into the lumen of the small intestine. In contrast three patients had normal amino acid uptake from the dipeptide solution and another absorbed both amino acids normally from the amino acid solution, in spite of concomitant sodium and water secretion.

\section{Dermatitis herpetiformis}

Patients with subtotal and partial villous atrophy had impaired sodium absorption from the amino acid solution $(P<0.05)$. Three out of six patients with subtotal and three out of nine patients with partial villous atrophy exhibited net secretion (values below $2 \mathrm{SD}$ of the normal mean). Compared with the normal control subjects there was no difference in sodium absorption from the dipeptide solution when the two groups with subtotal and partial villous atrophy were perfused, although two out of six patients with subtotal villous atrophy (one value below 2 SD of normal mean) and four out of nine patients with partial villous atrophy exhibited net secretion (values below 2 SD of normal mean). 
There was no significant difference in water absorption from either solution compared with the controls when both groups of patients with dermatitis herpetiformis were studied, although three out of six patients with subtotal villous atrophy (two values only below 2 SD of the normal mean) and three out of nine patients with partial villous atrophy secreted water into the lumen during the perfusion of the amino acid solution and two out of six patients with subtotal and three out of nine patients with partial villous atrophy secreted water during the dipeptide perfusions (all values below 2 SD of normal mean).

\section{Discussion}

The results show that there is considerable variation in the ability of individual patients with adult coeliac disease to absorb the amino acids and dipeptide from the upper jejunum using the perfusion technique. Some patients absorbed the amino acids and the dipeptide normally, some had impaired absorption of both, and a few failed to absorb either the amino acids or the dipeptide. One is surprised at the infrequency of impaired amino acid and dipeptide absorption, in view of the gross morphological changes seen in the upper jejunum of patients with adult coeliac disease, in particular reduced villous height and disturbance of absorptive cells. In contrast to these findings, the results of oral load experiments with glycine and glycylglycine (Craft et al, 1968), yeast protein, and yeast protein hydrolysate consisting of amino acids and small peptides (Crane and Neuberger, 1960a and b) suggested that patients with untreated adult coeliac disease absorbed amino acids and peptides poorly. The discrepancy in these results could just be due to the different experimental techniques used; a number of the patients studied using the oral load technique, however, had very severe symptoms and nutritional disturbances which suggests that they have had more severe functional impairment compared to some of our patients who on the whole did not complain of severe symptoms, and were referred on account of minor nutritional disturbances only. With a few exceptions our results are more in agreement with those of Richmond and Girdwood (1962) and Douglas and Booth (1969) who found no evidence of protein malabsorption in their patients after administering casein, gluten, and albumen orally, respectively. It thus seems likely that malabsorption of dietary protein only occurs in the severest affected cases of ault coeliac disease and ileal function studies will be needed to determine if these patients belong to a group who have concomitantly impaired ileal and jejunal function.

As it has been shown that jejunal mucosal peptide hydrolase activity is reduced in adult coeliac disease, impairment of dipeptide absorption could be more marked than that of amino acids (Sadikali, 1971). The kinetic advantage conferred by glycyl-L-alanine on glycine absorption seen in the normal controls was, however, maintained in the patients with untreated adult coeliac disease, even when absorption of both the dipeptide and amino acid were impaired. It is likely, therefore, that if maximally effective amino acid absorption is aimed at, especially in the severest cases of adult coeliac disease when the absorptive capacity of the intestine is reduced, the oral administration of mixtures of free amino acids is likely to be less satisfactory than the oral administration of enzymic hydrolysates of protein containing oligopeptides as well as free amino acids.

Although there were a few patients with dermatitis herpetiformis who had impaired amino acid uptake from both solutions, there was no significant difference in amino acid absorption from the two solutions when the groups of dermatitis herpetiformis patients with SVA and PVA were perfused compared with the normal control subjects. Under the described experimental conditions we have not been able to demonstrate a correlation between jejunal function and morphology as judged by a single jejunal biopsy, and there is no evidence to suggest that malabsorption of protein is likely to occur in dermatitis herpetiformis.

Ten individual experiments carried out using the described perfusion technique confirmed the results of other studies that only small amounts of sodium and water are absorbed when isotonic sodium chloride is perfused through the upper jejunum of normal subjects (Sladen and Dawson, 1969). In agreement with a recent report sodium and water absorption was significantly enhanced when isotonic solutions containing $10 \mathrm{mM}$ Gly-Ala and equivalent molar concentrations of the free amino acids were perfused (Hellier, Thirumalae, and Holdsworth, 1973).

The patients with adult coeliac disease varied in their ability to absorb sodium and water from the isotonic perfusion solutions. Some patients absorbed both sodium and water normally, whereas others had impaired absorption of both and a number exhibited net secretion of sodium and water into the lumen of the small intestine. Our results thus confirm the observation of other workers that the jejunal mucosa of patients with adult coeliac disease may be in a secretory state with respect to electrolyte and water movement (Fordtran, Rector, Locklear, and Ewton, 1967; Schmid, Phillips, and Summerskill, 1969; Russell, Allan, Gerskowitch, and Robertson, 1972). Not all our patients complained of abdominal symptoms or diarrhoea. There are two likely reasons 
for this: first some patients had normal solute, sodium, and water absorption from the upper jejunum, and secondly, as previously suggested, some of these patients could have normal or enhanced ileal function, resulting in efficient handling of abnormal loads of solute water and electrolytes which will be presented to the distal small intestine when the functioning of the jejunal mucosa is severely impaired (Schedl and Clifton, 1963).

The patients with dermatitis herpetiformis also varied in their ability to absorb sodium and water from the perfusion solutions, and there were patients with SVA and PVA who secreted sodium and water into the lumen of the upper jejunum. These findings clearly demonstrate that there may be functional impairment of the jejunal mucosa in dermatitis herpetiformis. None of these patients studied complained of abdominal symptoms or diarrhoea, and again the likely explanation is that some patients have normal jejunal function, and the patients with impaired jejunal function have either normal or enhanced ileal function.

We are grateful to the North East Metropolitan Regional Board and to the Board of Governors of St Bartholomew's Hospital for financial support, and we thank Professor Sir Eric Scowen for the use of his laboratory facilities. We should also like to thank Dr R. Marks and the clinicians of St John's Hospital for Skin Diseases for referring their patients, and Dr D. Munroe and Dr P. Borrie, who also referred patients to us.

\section{References}

Adibi, S. A. (1971). Intestinal transport of dipeptides in man: relative importance of hydrolysis and intact absorption. $J$. clin. Invest., 50, 2266-2275.

Asatoor, A. M., Cheng, B., Edwards, K. D. G., Lant, A. F., Matthews, D. M., Milne, M. D., Navab, F., and Richards, A. J. (1970). Intestinal absorption of two dipeptides in Hartnup disease. Gut, 11, 380-387.

Berg, N. O., Dahlqvist, A., Lindberg, T., and Nordén, Å. (1970). Intestinal dipeptidases and disaccharidases in celiac disease in adults. Gastroenterology, 59, 575-582.

Brow, J. R., Parker, F., Weinstein, W. M., and Rubin, C. E. (1971). The small intestinal mucosa in dermatitis herpetiformis. I. Severity and distribution of the small intestinal lesion and associated malabsorption. Gastroenterology, 60, 355-361.

Craft, I. L., Geddes, D., Hyde, C. W., Wise, I. J., and Matthews, D. M. (1968). Absorption and malabsorption of glycine and glycine peptides in man. Gut, 9, 425-437.

Crane, C. W., and Neuberger, A. (1960a). Absorption and elimination of ${ }^{16} \mathrm{~N}$ after administration of isotopically labelled yeast protein and yeast protein hydrolysate to adult patients with coeliac disease. I. Rate of absorption of ${ }^{15} \mathrm{~N}$ yeast protein and yeast protein hydrolysate. Brit. med. J., 2, 815-823.

Crane, C. W., and Neuberger, A. (1960b). Absorption and elimination of ${ }^{15} \mathrm{~N}$ after administration of isotopically labelled yeast protein and yeast protein hydrolysate to adult patients with coeliac disease. II. Elimination of isotope in the urine and faeces. Brit. med. J., 2, 888-894.

Crosby, W. H., and Kugler, H. W. (1957). Intraluminal biopsy of the small intestine: the intestinal biopsy capsule. Amer.J. dig. Dis., 2, 236-241.

Douglas, A. P., and Booth, C. C. (1969). Post prandial plasma-free amino acids in adult coeliac disease after oral gluten and albumin. Clin. Sci., 37, 643-653.

Douglas, A. P., and Peters, T. J. (1970). Peptide hydrolase activity of human intestinal mucosa in adult coeliac disease. Gut, 11, 15 17.

Fordtran, J. S., Rector, F. C., Locklear, T. W., and Ewton, M. F. (1967). Water and solute movement in the small intestine of patients with sprue. J. clin. Invest., 46, 287-298.

Hellier, M. D., Holdworth, C. D., McColl, I., and Perrett, D. (1972). Dipeptide absorption in man. Gut, 13, 965-969.

Hellier, M. D., Thirumalai, C., and Holdsworth, C. D. (1973). The effect of amino acids and dipeptides on sodium and water absorption in man. Gut, 14, 41-45.

Holdsworth, C. D., and Dawson, A. M. (1964). Absorption of monosaccharides in man. Clin. Sci., 27, 371-379.

Hydén, S. (1956). A turbidimetric method for the determination of higher polyethylene glycols in biological turbidimetric materials. K. Lantbr-Hogsk. Annlr., 22, 139-145.

Langley, R. (1968). Practical Statistics for Non-Mathematical People. Pan Books, London.

Lindberg, T., Nordén, Å., and Josefsson, L. (1968). Intestinal dipeptidases. Dipeptidase activities in small intestinal biopsy specimens from a clinical material. Scand. J. Gastroent., 3, 177-182.

Matthews, D. M. (1971). Protein absorption. J. clin. Path., 24, Suppl. (Roy. Coll. Path.), 5, 29-40.

Matthews, D. M., Craft, I. L., Geddes, D. M., Wise, I. J., and Hyde, C. W. (1968). Absorption of glycine and glycine peptides from the small intestine of the rat. Clin. Sci., 35, 415-424.

Purdie, J. W., Gravelle, R. A., Hanafi, D. E. (1968). Sulphur containing amino acids. II. Chromatography of disulphides and trisulphides with an automatic analyser. J. Chromat., 38, 346350.

Richmond, J., and Girdwood, R. H. (1962). Observations on amino acid absorption. Clin. Sci., 22, 301-314.

Rubino, A., Field, M., and Shwachman, H. (1971). Intestinal transport of amino acid residues of dipeptides. I. Influx of glycine residue of glycyl-1-proline across mucosal border. J. biol. Chem., 246, 3542-3548.

Russell, R. I., Allan, J. G., Gerskowitch, V. P., and Robertson, J. W. K. (1972). A study by perfusion techniques of the absorption abnormalities in the jejunum in adult coeliac disease. Clin. Sci., 42, 735-741.

Sadikali, F. (1971). Dipeptidase deficiency and malabsorption of glycylglycine in disease states. Gut, 12, 276-283.

Schedl, H. P. (1966). Use of polyethylene glycol and phenol red as unabsorbed indicators for intestinal absorption studies in man. Gut, 7, 159-163.

Schedl, H. P., and Clifton, J. A. (1963). Solute and water absorption by the human small intestine. Nature (Lond.), 199, 1264-1267.

Schedl, H. P., Pierce, C. E., Rider, A., and Clifton, J. A. (1968). Absorption of L-methionine from the human small intestine. J. clin. Invest., 47, 417-425.

Schmid, W. C., Phillips, S. F., and Summerskill, W. H. J. (1969). Jejunal secretion of electrolytes and water in non tropical sprue. J. Lab. clin. Med., 73, 772-783.

Silk, D. B. A., Perrett, D., and Clark, M. L. (1973). Intestinal transport of two dipeptides containing the same two neutral amino acids in man. Clin. Sci., 45, 291-299.

Sladen, G. E., and Dawson, A. M. (1969). Interrelationships between the absorptions of glucose, sodium and water by the normal human jejunum. Clin. Sci., 36, 119-132.

Sladen, G. E., and Dawson, A. M. (1970). Further studies on the perfusion method for measuring intestinal absorption in man: the effects of a proximal occlusive balloon and a mixing segment. Gut, 11, 947-954.

Stewart, J. S., Pollock. D. J., Hoff brand, A. V., Mollin. D. L., and Booth, C. C. (1967). A study of proximal and distal intestinal structure and absorptive function in idiopathic steatorrhoea. Quart. J. Med., 36, 425-444. 